Revista

Actualidades Investigativas

en Educación

\title{
Educación Técnica secundaria pública en Costa Rica: 1950-2014
}

\author{
Public secondary technical education in Costa Rica: 1950-2014
}

\author{
Volumen 20, Número 2 \\ Mayo - Agosto \\ pp. 1-35
}

\section{Gabriela Alvarado Calderón Raquel Mora Hernández}

Citar este documento según modelo APA

Alvarado Calderón, Gabriela. y Mora Hernández, Raquel. (2020). Educación Técnica secundaria pública en Costa Rica: 1950-2014. Revista Actualidades Investigativas en Educación, 20(2), 1-35. Doi. 10.15517/aie.v20i2.41668 


\title{
Educación Técnica secundaria pública en Costa Rica: 1950-2014
}

\author{
Public secondary technical education in Costa Rica: 1950-2014
}

\section{Gabriela Alvarado Calderón ${ }^{1}$ Raquel Mora Hernández ${ }^{2}$}

\begin{abstract}
Resumen: La Educación Pública Técnica Secundaria es una modalidad educativa costarricense, concebida como alternativa para la inserción temprana de la población joven en el mercado laboral. A pesar de su importancia en el plano nacional, no es tema central de las investigaciones existentes en materia educativa, que aborda más bien los aspectos como la oferta técnica del Instituto Nacional de Aprendizaje, especialidades técnicas, mercado laboral y evaluación por competencias -entre otros-, dejando de lado la formulación, orientación y ejecución de la política en Educación Técnica en sí. El presente artículo surge como resultado de Trabajo Final de Investigación para optar por el grado de Licenciatura en Trabajo Social de la Universidad de Costa Rica, y tiene como objetivo hacer una reconstrucción de los elementos principales de la política costarricense de Educación Técnica secundaria, desarrollada por el Ministerio de Educación Pública, en el periodo 1950-2014. La reconstrucción se guía por un modelo de análisis de política pública, fundamentado en la Teoría General de Sistemas, y con una metodología mixta de preponderancia cualitativa de alcances descriptivos y exploratorios. La población participante en estudio se compone por cinco profesionales del MEP con experiencia en la formulación e implementación de la política de Educación Técnica desde tres escenarios diferentes: los centros educativos, la Dirección de Educación Técnica Capacidades y Emprendedoras, y la función ministerial. La principal técnica de recolección de información corresponde al análisis documental de las memorias anuales de labores del MEP de 1950-2014, que se complementa con entrevistas semiestructuradas a profesionales del MEP. La investigación concluye que la Educación Técnica resulta más una aproximación al mercado laboral que una garantía real de inserción en el mismo, pues el mercado meta es incapaz de absorber toda la mano de obra que en ella se forma.
\end{abstract}

Palabras clave: educación técnica, política social, política pública, educación secundaria.

Abstract: Public Technical Secondary Education is a Costa Rican educational modality, conceived as an alternative for the early insertion of the young population in the labor market. Despite its importance at the national level, it is not a central theme of existing academic research about the education system, which rather addresses aspects such as the technical offer of the Instituto Nacional de Aprendizaje, technical specialties, the labor market and evaluation by competences -among others -, leaving aside the formulation, orientation and execution of the Technical Education policy itself. This article arises as a result of a research study to opt for the Bachelor of Social Work degree from the University of Costa Rica, and aims to reconstruct the main elements of the Costa Rican policy of Secondary Technical Education, developed by the Ministry of Public Education (MEP), in the period 1950-2014. The reconstruction is guided by a model of public policy analysis, based on General Systems Theory, and with a mixed methodology of qualitative preponderance of descriptive and exploratory scopes. The population participating in the study is made up of five professionals from MEP with experience in the formulation and implementation of the Technical Education Policy from three different scenarios: educational centers; the Direction of Technical Education, Capacities and Entrepreneurs; and the ministerial function. The main technique for collecting information corresponds to the documentary analysis of the annual reports of MEP's work from 19502014, which is complemented by semi-structured interviews with MEP's professionals. The research concludes that Secondary Technical Education is more an approximation to the labor market than a real guarantee of insertion in it, since the target market is unable to absorb all the labor that is formed.

Key Words: technical education, social policy, government policy, secondary education.

\footnotetext{
1 Universidad Nacional, Trabajadora Social, Costa Rica. Licenciatura en Trabajo Social, Universidad de Costa Rica. Dirección electrónica: raque.m.hdez@gmail.com Orcid https://orcid.org/0000-0002-0711-8349

2 Instituto Mixto de Ayuda Social, Trabajadora social, Costa Rica. Licenciatura en Trabajo Social, Universidad de Costa Rica. Dirección electrónica: gabrielitalda@gmail.com Orcid https://orcid.org/0000-0002-5337-9056
}

Artículo recibido: 6 de mayo, 2019

Enviado a corrección: 9 de marzo, 2020

Aprobado: 27 de abril, 2020 


\section{Introducción}

La educación es un derecho humano fundamental y en Costa Rica, se ha constituido en un elemento indispensable para promover el desarrollo humano, en tanto, comprende la preparación de las personas para participar de forma activa y efectiva en la vida social, política y económica, partiendo del ejercicio de derechos y el cumplimiento de deberes.

El alcance de tales objetivos es materializable mediante políticas públicas y específicamente la política educativa, tarea desempeñada principalmente por el Estado y acompañada de iniciativas de carácter privado; tales iniciativas -desde diferentes niveles y modalidades de educación-, asumen la responsabilidad de dotar al país de una oferta educativa pertinente a los desafíos contextuales (políticos, económicos y sociales) y conducirla hacia niveles de calidad.

Ante esto, el Ministerio de Educación Pública (MEP) pone a disposición de la población, mallas curriculares que incluyen los niveles de preescolar, primaria, secundaria (en modalidad académica y técnica) y superior. Cada uno de estos niveles educativos es de relevancia, sin embargo, la educación secundaria se reviste de gran importancia, en tanto brinda la posibilidad al estudiantado -una vez concluido el ciclo de estudios- de optar por la educación superior o insertarse en el mercado de trabajo (dada la especialización de estudiantes en un área de interés y la puesta en práctica de los conocimientos en diversas experiencias en centros de trabajo); ambas opciones posibles mediante la obtención del título de Bachillerato en Educación Media, en la modalidad académica o complementaria a éste, el título de Técnico Medio cursando la modalidad técnica.

La Educación Técnica es una modalidad educativa estratégica para el país y para las personas que acceden a ella. Para el país, porque le permite incrementar su competitividad, al generar los recursos humanos capacitados que la economía necesita. Para las personas, porque ofrece a la población joven una opción de estudio que amplía sus oportunidades futuras de obtener empleos e ingresos dignos, así como sus posibilidades de continuar con éxito el proceso formativo (Programa Estado de la Nación, 2011, p.236).

En este sentido, se coloca a la modalidad técnica como vía indiscutible para alcanzar mejores condiciones de vida. Sin embargo, a nivel investigativo los documentos existentes mencionan a grandes rasgos el tema, siendo lo principal la discusión sobre la política educativa en general y su doble funcionalidad: como estrategia estatal que beneficia a sectores sociales que han sido excluidos históricamente, por un lado, y como un conjunto de acciones que tienden más a dar respuesta a los intereses particulares del mercado, por el 
otro; el papel que juega el Estado en la respuesta -o no- ante las demandas de los sectores vulnerabilizados, partiendo del supuesto que el objetivo final de la política educativa debe ser formar el recurso humano necesario que contribuya con el desarrollo económico y social del país, y deja de lado las necesidades educativas de poblaciones específicas.

De igual manera, la discusión se centra en los mecanismos de financiamiento incluyendo la influencia de organismos internacionales que juegan papeles importantes en la definición de la Educación Técnica-, así como la "Evaluación por competencias" y la gestión de la oferta programática de los Colegios Técnico -profesionales- afirmando que los currículos educativos se encuentran descontextualizados socioeconómica y educativamente de las comunidades en las que se insertan (Cordero y Leal, 1987, p.6). Subyacen, además, aportes sobre los factores que influyen en el abandono escolar en sétimo año de algunos colegios técnicos, así como la existencia de determinantes específicos en ciertos contextos que vislumbran la discordancia entre la oferta y las necesidades del entorno.

A partir de lo revisado con las producciones existentes, se puede concluir, que las investigaciones se encuentran desfasadas respecto al contexto actual, por lo que resulta necesario discutir la temática a la luz de las condiciones sociales, económicas, políticas y culturales del momento en que se desarrollaron acciones que impactaron en la formulación de dicha política, comprendiendo que cada una de ellas debía responder al mismo contexto; es necesario acoger la discusión sobre la actualización y cambio del subsistema de Educación Técnica secundaria desde una perspectiva que considere al estudiantado y docentes, y no solamente la visión empresarial y de mercado.

Sin embargo, los datos no son comprensibles si no se conceptualiza de manera previa la Educación Técnica como modalidad de estudio propuesta por el MEP, como máxima autoridad en el tema, por lo que resultó fundamental para el equipo de investigación realizar una reconstrucción histórica de la política que legitima la modalidad mencionada, de manera que se identificaran elementos políticos, culturales, económicos y sociales de la coyuntura nacional e internacional y se pudieran contrastar con las transformaciones que ha sufrido la misma durante el periodo de estudio. En este sentido, se planteó como problema de investigación ¿Cuáles han sido las transformaciones de la política pública en materia de Educación Técnica secundaria pública y su correspondencia con las condiciones económicas, sociales y políticas de Costa Rica?

De igual manera, para dar respuesta a dicha interrogante, se definió como objetivo general reconstruir la política pública en Educación Técnica secundaria, desarrollada por el 
MEP, materializada en tres objetivos específicos que permitieran obtener los siguientes resultados: 1 debatir en torno a los fundamentos teóricos de la Educación Técnica, 2 determinar las condiciones del contexto costarricense en sus dimensiones política, económica, jurídica y social vinculadas a la modalidad, 3 caracterizar las transformaciones de la política, a partir de la indagación en los niveles de gestión y ejecución de la misma.

\section{Referente teórico}

La investigación que generó el presente artículo tuvo como base teórica la Teoría General de Sistemas, que permite entender que en las políticas públicas intervienen gran número de factores humanos, económicos, sociales, políticos, jurídicos e incluso culturales, fuertemente interconectados, que a nivel de gestión se ven reflejados en la organización, planificación, control, resolución de problemas y toma de decisiones que buscan la materialización de sus objetivos.

En este sentido, la política pública es comprendida como un sistema, compuesto por múltiples elementos que tienen su propia dinámica pero que se afectan unos a otros, en tanto retomando a Paredes (2008) los sistemas contienen "[...] un conjunto de elementos en interacción dinámica en el que el estado de cada elemento está determinado por el estado de cada uno de los demás que lo configuran" (s.p).

El sistema, según Ferdinand de Saussure (1931), "es una totalidad organizada, hecha de elementos solidarios que no pueden ser definidos más que los unos con relación a los otros en función de su lugar en esa totalidad" (c.p en Paredes, 2008, s.p), por lo que se sostiene que el todo es más que la simple suma de las partes. Lo cual sugiere que los distintos elementos que subyacen a un fenómeno se encuentran relacionados entre sí y no pueden comprenderse al margen de las conexiones entre estos.

Sobresalen aspectos referentes a elementos diversos e interconectados entre sí que conforman una unidad global y comparten objetivos comunes. Siendo fundamental la comprensión de otros conceptos tales como, subsistemas, entradas (inputs), salidas (outputs), retroalimentación y caja negra. Se identifica a un subsistema porque está conformado por algún conjunto de elementos de un sistema que se relacionan entre ellos y por tanto lo hacen identificable y distinto a los otros.

Por otra parte, un sistema puede ser cerrado (cuando no intercambia información y energía con su entorno, aunque éste a lo interno experimente cambios) o abierto (cuando 
intercambia información y energía con su entorno, por lo que es modificado y a la vez modifica a ese mismo contexto) (Paredes, 2018; Johansen, 1981).

Además, es necesario contemplar que los sistemas -independientemente de que sean cerrados o abiertos- poseen fronteras, las cuales según Johansen (1981) son "[...] aquella línea que separa el sistema de su entorno (o supersistema) y que define lo que le pertenece y lo que queda fuera de él [...]" (p.68).

Esta teoría de análisis de la realidad tiene algunas ventajas, "[...] pues la función del sistema puede identificarse con los rendimientos de transformación y las condiciones internas de esta transformación se consideran entonces, como una estructura [...]" (Luhmann, 1984, pp.192-193). La estructura no se encuentra dada per sé, pues ésta es una interpretación que se realiza de la realidad a partir de esta última, donde la cultura es un elemento fundamental a considerar en la gestación, formación, consolidación y cambio de la misma.

Es a partir de estas aclaraciones que puede entenderse que la perspectiva sistémica en el análisis de política pública permite la comprensión de esta como un sistema en el que los elementos están correlacionados directamente y que forman subsistemas individuales, que pueden afectarse entre sí y por tanto afectar a la política como tal.

Según Parsons (2007), las políticas públicas "se ocupan de aquellas esferas consideradas como públicas", siendo así que su idea "presupone la existencia de una esfera o ámbito de la vida que no es privada o puramente individual, sino colectiva"; por lo tanto, lo público, "comprende aquella dimensión de la actividad humana que se cree que requiere la regulación o intervención gubernamental o social, o por lo menos la adopción de medidas comunes" (p.37).

En este sentido y partiendo de la perspectiva sistémica, lo público como escenario que determina la existencia de las políticas públicas, constituye un sistema dentro del suprasistema -entendido en este caso como la educación-, en el que interactúan actoras y actores tanto políticos como civiles que determinan el curso de sus acciones. Por tanto, por política pública "[...] puede entenderse un campo de acción del estado, una declaratoria de intención, un proceso de conversión, un ciclo de acción y un conjunto de impactos que pretenden tener consecuencias sobre la sociedad y requieren para ello acciones de la administración pública [...]" (Parsons, 2007, p.1).

Ahora bien, para efectos de la presente investigación, la política pública fue entendida como "un proceso integrador de decisiones, acciones, inacciones, acuerdos e instrumentos 
[...] encaminados a solucionar o prevenir una situación definida como problemática" (Velásquez, 2009, p.156) o un tema problematizado² en el ámbito público ya sea por autoridades políticas o la sociedad civil.

Además, se reconoce a la política pública como un sistema abierto, que no se encuentra aislado, sino que "hace parte de un ambiente con el que se interrelaciona y sin el cual no puede existir" (Velásquez, 2009, p.166). Dicho ambiente se compone de múltiples elementos; entre ellos, "el sistema político dentro del cual se forma y que está integrado por el ordenamiento jurídico, por las organizaciones públicas y por las comunidades que se benefician o se ven afectadas por la política misma" (Velásquez, 2009, p.167), a lo que es posible sumar las fuerzas internas y externas -económicas, políticas, sociales y culturalesque inciden en su definición. En este sentido, la política pública se convierte en un escenario complejo en el que cada elemento -actoras y actores sociales- instrumentos-Estado- genera múltiples relaciones que están mediadas por factores ideológicos y estructuras de poder.

Bajo este marco referencial, la política educativa puede ser comprendida como los cursos de acción por medio de los cuales se pretende impulsar determinados programas e iniciativas, con el fin de promover la educación dentro del territorio nacional y resolver problemas específicos de la misma; presenta como punto de partida la integración de lo jurídico, las disposiciones nacionales e internacionales relativas al derecho a la educación establecidas en la Constitución Política de Costa Rica, Leyes y Decretos, Declaración Universal de los Derechos Humanos, Pactos y Convenciones internacionales; instrumentos que le atribuyen características como obligatoriedad, gratuidad y universalidad.

De igual forma, toma en cuenta las circunstancias societales, así como la economía, las organizaciones, la cultura, la comunidad, la nación y el interés de los grupos poblacionales, quedando "sujeta a influencias y cambios que no solo tiene que ver con la reducción de la división social del trabajo y la estructura de clases, sino con las relaciones de poder entre los grupos en el propio aparato político" (Ishizaka, 2011, p 23).

Además, la política educativa se construye según los presupuestos del proyecto de sociedad que para cada Estado o país depara un momento histórico determinado, a partir de su estructura social, económica, institucional e ideológica. Enmarca la relación entre la

\footnotetext{
2 Por tema problematizado se entiende un espacio o ámbito en el que el Estado puede intervenir, sin que necesariamente constituya un problema social, colocando como ejemplo el caso de la educación y la creación de todo un sistema que le permitiera al país contar con una población instruida en aras de su desarrollo. Sin embargo, lo anterior no implica que al interior de dicho tema no se presenten problemas o situaciones críticas que tanto la sociedad civil como el Estado deban problematizar y decidir o no intervenir en ellas.
} 
educación, el sistema económico, un régimen político y su legitimidad, que requiere de la transmisión de valores, cultura y conocimientos que respondan a un constructo ideológico que delinea un proyecto societal, y en lo específico a la educación su función o contribución en la construcción de dicho proyecto, ya sea como una iniciativa de gobierno, de Estado e incluso una exigencia del mercado que busca materializar una serie de decisiones y de acciones que requieren de la creación de un sistema educativo o su readecuación a los determinantes contextuales para la formación de las personas que se van a desenvolver en dicho contexto.

Es así, que el ubicar las modalidades educativas -formales, no formales, informales- en este escenario, demanda partir de la comprensión de la educación como un suprasistema dotado de una fuerte intencionalidad política e ideológica, que procura no sólo la transmisión de conocimientos, sino la dotación del recurso humano que se requiere para el desarrollo del país. A partir de esta intencionalidad ideológica y los cambios políticos que se presentan tanto a nivel nacional como internacional, Costa Rica establece su política educativa en aras de procurar un avance que propicie el desarrollo societal a futuro, que actualmente "se basa en una visión integral del ser humano como parte de su fundamentación filosófica enfocada en el humanismo, el racionalismo y el constructivismo" (MEP, 1994, s.p).

A partir de lo anterior en Costa Rica, la Educación Técnica se concibe como la "[...] encargada de brindar oportunidades a los estudiantes en el ámbito universitario y de secundaria para la adquisición de conocimientos y habilidades en un área específica, la cual capacita al estudiante para iniciar exitosamente su incursión en el campo laboral [...], se ofrece a quienes deseen obtener formación en carreras profesionales de grado medio" (Cox, 2005, p.14).

Por tanto, es una modalidad de educación formal que pretende generar en el estudiantado la integración de conocimientos y habilidades en un área específica, en materia de aproximación al mundo laboral; formación que puede derivar en la inserción temprana al mercado de trabajo a la vez que se dan estudios a nivel superior o cada una de las opciones por separado. Incluye el desarrollo de conocimientos generales a nivel académico y especializado en una rama técnica concreta.

Por su parte el MEP (s.f) en su página web señala que:

(...) la Educación Técnica Profesional es un subsistema del sistema educativo formal, cuyo origen se establece en la Ley Fundamental de Educación No. 2298, Art 17, del 22 de noviembre de 1958. Representa una alternativa de formación integral, para 
aquellas mujeres y hombres que desean incorporarse al campo laboral. Proporciona igualdad de oportunidades en términos de acceso equitativo y no discriminatorio, pues ofrece diversas especialidades en los diferentes Colegios Técnicos Profesionales del país (...) (Educación Técnica, párr.1-2).

En otras palabras, la Educación Técnica es una herramienta con la cual se pretende capacitar a la población de manera rápida para insertarse en el mercado laboral a la mayor brevedad posible. Está diseñada y orientada desde la gran esfera que es la educación y el derecho fundamental del acceso a esta, con la finalidad de brindar a las personas la capacitación y los conocimientos necesarios para desempeñarse en alguna de las especialidades que ofrece el sistema educativo debido a la demanda del mercado.

Por tanto, la Educación Técnica costarricense en sus planteamientos busca generar movilidad social conformándose esta como "un instrumento para facilitar el desarrollo económico, social y tecnológico, gracias a la capacitación del recurso humano con base en las necesidades cambiantes del mercado laboral tal y como se resalta en la conferencia mundial de la UNESCO de 1989" (López et al, 2001, p.62).

Por ende, en el mejor de los escenarios, estudiantes que formen parte de esta modalidad educativa reciben además formación desde una visión humanística, motivo por el cual y según la visión del MEP, al finalizar los estudios a nivel de secundaria, la o el joven puede incorporarse al campo de trabajo o continuar estudios de nivel superior si así lo desea, con dos títulos que lo acreditan como: Técnico en el nivel medio en la especialidad seleccionada y también como Bachiller en Enseñanza Media.

Por tal motivo, se considera así, la Educación Técnica como una herramienta de crecimiento personal en la que se conjugan formación, vocación y trabajo, lo que a su vez permite "la preparación y perfeccionamiento de hombres y mujeres a través de la formación de competencias profesionales en determinados ámbitos productivos" (Calderón, 2015, p 4).

Sin embargo, para el equipo investigador la Educación Técnica secundaria es: una modalidad de educación formal que pretende generar en la población estudiantil la integración de conocimientos y habilidades en un área específica, en materia de aproximación al mundo laboral, sin resultar en un simple adiestramiento vocacional o tecnicista; formación que puede derivar en la inserción temprana al mercado de trabajo a la vez que se dan estudios a nivel superior o cada una de las opciones por separado. Incluye el 
desarrollo de conocimientos generales a nivel académico y especializado en una rama técnica concreta.

\section{Metodología}

\subsection{Enfoque de la investigación}

En este estudio se utilizó una metodología mixta es decir; se combinaron tanto aspectos cualitativos como cuantitativos, en la cual según Baptista et al (2010) "la meta de la investigación mixta no es reemplazar a la investigación cuantitativa ni a la investigación cualitativa, sino utilizar las fortalezas de ambos tipos de indagación combinándolas y tratando de minimizar sus debilidades potenciales" (p.545). Sin embargo, el estudio fue, siguiendo a Baptista et al (2010) preponderantemente cualitativo, porque implicó el análisis de la política desde múltiples lecturas de fuentes documentales, así como de entrevistas semiestructuradas, complementando lo anterior con datos numéricos derivados de indicadores empíricos o brutos aportados principalmente por el MEP, con el fin de contrastar los conceptos abstractos derivados de los datos cualitativos.

Cabe aclarar, que los datos cuantitativos se recolectaron y analizaron de forma simultánea con los cualitativos pero sin recurrir a ningún instrumento de medición, sino que fueron extraídos de las fuentes documentales y se expusieron de forma integrada mediante el uso de cuadros y otros entremezclados con los cualitativos para guardar su esencia.

Los alcances de la investigación fueron tanto exploratorios como descriptivos. Exploratorios en tanto correspondió a un acercamiento inicial a su objeto de estudio, porque que como se ha mencionado, la Educación Técnica secundaria pública, antes de la presente investigación no había sido colocada como objeto central de estudio. Se asumió como descriptivo, pues éstos "buscan especificar las propiedades, las características y los perfiles de personas, grupos, comunidades, procesos, objetos o cualquier otro fenómeno que se someta a un análisis" (Baptista et al, 2010, p.80).

\subsection{Población}

Se consideró de suma importancia para la investigación contar con el criterio de profesionales del MEP con experiencia en la formulación e implementación de la Educación Técnica desde tres escenarios diferentes; los centros educativos, la Dirección de Educación Técnica Capacidades Emprendedoras (DETCE) y la función ministerial. Las personas entrevistadas ocupaban los siguientes puestos: 1 docente de Educación Técnica del MEP, el 
ex Ministro de Educación (2006-2014), la Asesora Nacional de Educación Técnica (2014), el Director actual de la DETCE (2014), el ex Director de la DETCE (1994-2014).

\subsection{Técnicas de recolección de información}

\subsubsection{Análisis documental}

La principal técnica de recolección de información fue el análisis documental, para el cual se elaboraron tres tipos de instrumentos, dos en forma de matriz y una base de datos. La matriz \#1 Estado del Arte; permitió desglosar y recuperar elementos de Trabajos Finales de Graduación como: el objeto de investigación y su respectiva justificación, los objetivos, el problema a investigar, el encuadre teórico utilizado, la metodología y las técnicas, los hallazgos/resultados y las conclusiones, esto con la finalidad de determinar cómo había sido tratado el tema a nivel investigativo.

La base de datos de periódicos consistió en el registro de noticias en relación con el tema por año y mes de cada década; con el fin de incursionar en el posicionamiento sobre la Educación Técnica de actores/as sociales y políticos externos al MEP con interés en la temática, así como en la forma en que la misma fue presentada a la sociedad desde estos medios de comunicación.

Finalmente, la matriz \#3 Memorias MEP; desglosa las categorías definidas para la reconstrucción de la política -contexto, actores/as, agenda política, recursos, estructura organizativa-, en razón de analizar el entorno en que se desenvolvió y sus transformaciones en relación a los niveles de gestión y ejecución.

Ahora bien, al definirse un periodo de estudio tan amplio, se determinó la necesidad de abordar el tema por décadas hasta 1990, y el subperiodo 2000-2014 (14 años), y que cada momento histórico fuera asignado a una investigadora e investigador ${ }^{3}$ con la finalidad de que estudiara a profundidad los elementos definitorios de las categorías propuestas en el modelo de análisis - presentado a continuación- a la luz de los determinantes económicos, sociales y políticos del contexto costarricense (Tabla 1).

\footnotetext{
${ }^{3}$ El equipo investigador estuvo conformado por Gabriela Alvarado; Juan José Araya; Deiner Elizondo; Raquel Mora; Pamela Solano y Jeimy Peralta, quienes con el tema "Educación Técnica secundaria pública en Costa Rica: 1950-2014" optaron por el grado de Licenciatura en Trabajo Social en la Universidad de Costa Rica en 2016.
} 
Tabla 1. Principales fuentes de información según momento histórico

\begin{tabular}{|c|c|c|}
\hline Década & Fuentes Primarias & Fuentes secundarias \\
\hline 1950 & $\begin{array}{l}\text { Memoria anual de labores 1951-1959. } \\
\text { Leyes, reglamentos, normas, relativas a la Educación } \\
\text { Vocacional. } \\
\text { Periódicos: La República, La Nación, La Prensa Libre. }\end{array}$ & $\begin{array}{l}\text { Libros y revistas } \\
\text { atinentes al tema. }\end{array}$ \\
\hline 1960 & $\begin{array}{l}\text { Memoria anual de labores } 1960-1967 . \\
\text { Leyes, reglamentos, normas relativas a la Educación } \\
\text { Vocacional. } \\
\text { Plan de desarrollo económico y social de Costa Rica } \\
1965-1968 \text { y } 1969-1972 . \\
\text { Previsiones del Desarrollo Económico y Social } 1969 \text { - } \\
1972 . \\
\text { Periódicos: La República, La Nación, La Prensa Libre. }\end{array}$ & $\begin{array}{l}\text { Libros, y revistas } \\
\text { atinentes al tema. }\end{array}$ \\
\hline 1970 & $\begin{array}{l}\text { Memoria anual de labores 1971-1979. } \\
\text { Leyes, reglamentos, normas relativas a la Educación } \\
\text { Técnica Profesional. } \\
\text { Plan Nacional de Desarrollo 1974-1978 y 1979-1982. } \\
\text { Periódicos: La República, La Nación, La Prensa Libre, } \\
\text { Semanario Universidad. }\end{array}$ & $\begin{array}{l}\text { Libros y revistas } \\
\text { atinentes al tema. }\end{array}$ \\
\hline 1980 & $\begin{array}{l}\text { Memoria anual de labores } 1980-1989 . \\
\text { Leyes, reglamentos, normas relativas a la Educación } \\
\text { Técnica Profesional. } \\
\text { Plan Nacional de Desarrollo } 1982-1986 \text { y 1986-1990 } \\
\text { Periódicos: La República, La Nación, La Prensa Libre, } \\
\text { Semanario Universidad. }\end{array}$ & $\begin{array}{l}\text { Libros y revistas } \\
\text { atinentes al tema. }\end{array}$ \\
\hline 1990 & $\begin{array}{l}\text { Memoria anual de labores } 1990-1999 . \\
\text { Leyes, reglamentos, normas relativas a la Educación } \\
\text { Técnica Profesional. } \\
\text { Plan Nacional de Desarrollo 1990-1994, 1994-1998, } \\
\text { 1998-2002. } \\
\text { Periódicos: La República, La Nación, La Prensa Libre, } \\
\text { Semanario Universidad. }\end{array}$ & $\begin{array}{l}\text { Informes Estado de la } \\
\text { Nación en Desarrollo } \\
\text { Humano } \\
\text { 1994-1999. }\end{array}$ \\
\hline 2000 & $\begin{array}{l}\text { Memoria anual de labores } 2001-2014 . \\
\text { Leyes, reglamentos, normas relativas a la Educación } \\
\text { Técnica Profesional. } \\
\text { Plan Nacional de Desarrollo 2002-2006, 2006-2010, } \\
2011-2014 . \\
\text { Periódicos: La República, La Nación, La Prensa Libre, } \\
\text { Semanario Universidad. } \\
\text { Entrevistas a informantes clave. }\end{array}$ & $\begin{array}{l}\text { Informes Estado de la } \\
\text { Nación en Desarrollo } \\
\text { Humano Sostenible } \\
2000-2014 \text {. de la } \\
\text { Estado de lón } \\
\text { Educación 2005-2015. }\end{array}$ \\
\hline
\end{tabular}

Fuente: Alvarado, Gabriela; Araya, Juan José; Elizondo, Deiner; Hidalgo, Pamela; Mora, Raquel, Peralta, Jeimy. (2016)

\subsubsection{Entrevistas semiestructuradas}

Se realizaron entrevista semiestructuradas, con guías de preguntas generales respecto al proceso de formulación e implementación de la política educativa en Educación Técnica secundaria y la especificidad del cargo desempeñado por cada una de las personas definidas como informantes clave. Cabe resaltar acá, que ante las escasas posibilidades de 
que informantes claves contaran con conocimientos del tema en estudio en todo su periodo de análisis (1950-2014), se determinó que las entrevistas estarían enfocadas en dar respuesta a los vacíos identificados en el análisis documental del subperiodo 2000-2014. Las personas profesionales del MEP fueron contactadas por vía electrónica y entrevistadas en sus espacios de trabajo u otro lugar a convenir, según su disponibilidad de tiempo.

\subsubsection{Análisis de la información}

En la investigación se utilizó tanto la triangulación como el análisis de la información. La triangulación "es el proceso mediante el cual se valida la información recolectada, al aplicar distintos métodos y técnicas de investigación para evidenciar y constatar semejanzas y diferencias entre los datos e informaciones" (Baptista et al, 2010). El análisis de la información implica una labor reflexiva por parte del equipo investigador, al respecto a los resultados obtenidos y a la luz de la teoría para generar conclusiones y recomendaciones.

\subsubsection{Construcción de un modelo de análisis}

El equipo investigador consideró que la mejor forma de entender el proceso de producción e implementación de las políticas públicas y alcanzar un análisis riguroso del mismo, era contar con un modelo de análisis, ya fuera mediante la escogencia de alguna de las propuestas realizadas por personas versadas en la materia o la construcción de un modelo propio retomando elementos de uno o varios de ellos, por lo que se llevó a cabo un proceso de revisión de las propuestas que se consideraron aportaban mayores elementos para el debate interno y el análisis de la Educación Técnica, a saber: O'Donnell y Oszlak, (1981), Hinojosa, Larrue, Knoepfel, y Varonne (2007), lamamoto (2003), Molina y Morera (2005), optando finalmente por elaborar una propuesta propia. No sé si aquí va el nombre o solo el apellido, pero todo está abajo

El modelo re-construido por el equipo investigador fue fundamentado en la Teoría General de Sistemas que tomó como base los aportes de Molina y Morera (2005), que parte de una perspectiva sistémica que concibe la política pública como un sistema abierto constituido por los siguientes elementos: a) componentes (lineamientos, objetivos, estrategias, acciones, programas y proyectos); b) instituciones públicas y privadas involucradas en los niveles de formulación, ejecución y evaluación; c) recursos humanos, materiales y financieros; d) grupos meta o beneficiarios y; e) condicionantes externos (políticos, económicos y sociales) (p.4) 
Sin embargo, algunos fueron modificados, ya sea en nomenclatura o en contenido para incluirlos en categorías más amplias; de igual manera se plantearon algunas categorías más, a fin de establecer una propuesta que incluyera la mayor cantidad de componentes para un análisis a profundidad de la política educativa en Educación Técnica secundaria pública, a saber:

- Contexto: refiere a los condicionantes económicos, políticos, jurídicos y sociales, que determinaron el funcionamiento -adecuado o no- de las políticas definidas en el periodo en estudio.

- Inclusión del tema en la agenda política: refiere a las discusiones sobre la Educación Técnica secundaria en el ámbito estatal, a fin de considerar en qué momentos históricos cobró mayor fuerza dentro de la agenda política nacional y a nivel coyuntural.

- Componentes: incluye lineamientos, objetivos, estrategias, acciones, programas y proyectos que se enmarcan en la política, para comprender las inflexiones que se hicieron durante cada década, vinculadas con el contexto expuesto anteriormente.

- Actoras y actores sociales involucrados: corresponde al análisis de los grupos involucrados en la formulación e implementación de la política, los intereses/beneficios de cada uno de ellos, las alianzas estratégicas que se realizaron para el logro de los objetivos, así como los obstáculos y trabas que resultaron de las mismas.

- Recursos utilizados: comprende tres tipos de recursos indispensables para la implementación de la política a saber; humanos, materiales y los financieros.

- Características de la población meta: analiza la correspondencia entre las características de la población meta -haciendo énfasis en la población estudiantil- y los programas y proyectos definidos desde la política en Educación Técnica secundaria pública, a fin de identificar la visión que se ha tenido sobre ellas y ellos como público meta.

- Estructura organizativa: refiere a los cambios realizados en la estructura del MEP y en lo específico a la modalidad Vocacional y/o Técnica Profesional, con el fin de hacer notar los cambios en los nombres de la entidad encargada del tema, así como la modificación de las funciones asignadas en cada periodo histórico.

\subsection{Procesamiento $y$ análisis}

El acercamiento al objeto de estudio demandó en primer momento aplicar la técnica de análisis documental, cumpliendo con los siguientes pasos: 
1. División del estudio de la política según la delimitación temporal: cada década y el subperiodo fueron asignadas a una o un integrante del equipo, para que ahondara en el estudio de los elementos definitorios de las categorías propuestas en el modelo de análisis.

2. Elaboración de matrices: cada integrante del equipo a partir de la década o el subperiodo asignado procedió a la elaboración de la matriz \#3 Memorias MEP y la base de datos de periódicos de circulación nacional para su revisión. En el caso de las restantes fuentes primarias y las secundarias, cada investigadora e investigador hizo una selección según su pertinencia para el momento histórico analizado y realizó una lectura en profundidad de su contenido.

Una vez finalizado este primer gran momento, se procedió a aplicación de la técnica de la entrevista semi-estructurada que implicó el contacto con las personas informantes, la elaboración de guías de entrevistas, aplicación de entrevistas y sistematización de los resultados.

El tercer y último momento, correspondió al análisis de la información obtenida y se utilizó la técnica de triangulación de la información, por medio de la integración de los resultados a partir del trabajo de campo; entrevistas a personas expertas y análisis bibliográfico. Esta fase fue desarrollada de forma simultánea con la segunda, en lo específico al primer momento de análisis documental, lo que implicó cumplir con los siguientes pasos:

1. Cada década y el subperiodo fueron sometidos a un análisis individual y de tipo descriptivo por la persona investigadora designada; en primer momento en lo referente a la categoría contexto, y en segunda instancia a la agenda política, los componentes, la estructura organizativa, actores, los recursos utilizados y la población meta.

2.Se realizaron discusiones grupales, para poner en común los resultados de los análisis individuales y estructurar la presentación general de la información.

3. A partir del análisis general se elaboró una síntesis analítica de cada apartado del modelo con los principales hallazgos de la investigación.

4. Finalmente se elaboraron las conclusiones y recomendaciones.

Es importante señalar, que en el proceso de investigación se presentó como una gran limitación que en las principales fuentes de información es decir; las memorias del MEP, se encontraron importantes vacíos respecto a cada uno de los elementos que se definieron para 
el análisis de la política, porque en algunas décadas no se presentaron informes referentes a las labores desarrolladas por dicho Ministerio o no se registró información en relación a ellas, en este sentido no se contó con la misma disponibilidad de fuentes de información para todas las décadas, por lo que las posibilidades de comparación y contraste de los datos no fueron las mismas para cada periodo histórico.

\section{Análisis de los resultados}

Para este apartado, se presentan los hallazgos de las transformaciones de la política, a partir de la indagación en los niveles de gestión y ejecución de la misma en bloques que incluyen la totalidad de las categorías de análisis del modelo propuesto por el equipo investigador, con el fin de facilitar la comprensión por parte de la persona lectora. Sin embargo, se separan por décadas, según eventos históricos que provocaron inflexiones tanto a nivel contextual, como de política pública.

Ahora bien, para iniciar el recorrido por los albores de lo que actualmente comprendemos como Educación Técnica, es necesario que se haga un recuento breve sobre lo que sucedía antes de 1950, porque a finales de la década de los años 70 del siglo $\mathrm{XIX}$, se registran los primeros aspectos relacionados con la modalidad de estudio, en un contexto liberal donde primaba la educación secundaria esencialmente académica, con un corte elitista que favorecía la exclusión y el rezago.

En este sentido para 1870 bajo un modelo de desarrollo económico basado en la producción de café y banano, complementado con la caña de azúcar y tabaco, según Quesada (2005), predominaba la instrucción básica de la población y "el sistema educativo no concordaba plenamente con las necesidades del modelo agroexportador [...]" (p.14), en tanto el Estado carecía de cuadros profesionales y/o técnicos necesarios para el desarrollo de dicha economía, por lo que "existía ámbito profesional para la abogacía y la carrera eclesiástica, pero estaba ausente la formación académica de ingenieros civiles, agrimensores, arquitectos, agricultores y metalurgistas, que realizaran las funciones de [...]: apertura y perfeccionamiento de vías de comunicación, explotación de minas y desarrollo de la agricultura comercial" (Quesada, 2005, pp. 13-14).

En ese periodo, para subsanar la falta de preparación del sector trabajador aparecieron proyectos como las escuelas de Agricultura, Artes Mecánicas y Oficios -creada en 1886 (Rojas, 1977, p.1), el Liceo de Costa Rica -creado en 1887- y el Colegio Superior de Señoritas -creado en 1888- sin que eso significara la existencia de políticas alternativas de 
educación ni una estructura para atender necesidades emergentes. Los últimos dos centros educativos mencionados, intentaron establecer escuelas de comercio -en el de mujeres- y las de Agricultura y Comercio en el liceo, sin embargo, dichas propuestas no tardaron más de dos años en desaparecer, pues no contaban con suficientes recursos ni estudiantes matriculados (Cartera de Instrucción Pública, 1905, p. X)

El Estado retomó el acercamiento a estrategias más allá de lo académico, con la división del Liceo de Costa Rica en cinco secciones a saber: Humanidades, Normal, Agrícola, Comercial y Técnica, otorgando títulos respectivamente de; Bachiller, Maestro Normal, Certificado de aptitud para las labores agrícolas, Certificado de Estudios Comerciales y Maestro de obras, este último con el fin de formar en trabajos vinculados a la Ingeniería y la Agricultura (Cartera de Instrucción Pública, 1906, p.38). En el caso de la instrucción femenina fue establecida una Escuela de Tipografía vía Acuerdo N0 155 del 28 de julio de 1906, la cual otorgaba el título de "Oficialas de Tipografía" (Cartera de Instrucción Pública, 1906, p.51).

En 1908 se introdujo el modelo Salesiano, en la Escuela de Artes y Oficios Salesiana, en Cartago, con un énfasis en muchachos de "escasos recursos". Se intentaron algunas otras estrategias: Escuela de Agricultura -1914-, Escuela Nacional de Agricultura (posteriormente, en 1940, Escuela de Agronomía de la Universidad de Costa Rica, la Escuela de Artes y Oficios en Alajuela -en 1941-, la Escuela Técnica Nacional y la Escuela de capacitación industrial -en 1948, como iniciativas privadas- y la Escuela Taller de Limpiabotas -en 1949- (Rojas, 1977, pp. 1-3).

Ahora bien, 1949 el MEP -anteriormente Cartera de Instrucción Pública y después Secretaría de Educación Pública- nombró un Comité de Educación Vocacional -como se le denominó a la formación paralela a la académica enfocada en Artes y Oficios- "que realiza varias investigaciones acerca de la necesidad de mano de obra en el país" (Rojas, 1977, p.3) la cual sentó un precedente respecto a la Educación Vocacional a nivel de secundaria, en tanto conllevó la realización de nuevas investigaciones y análisis respecto a este tipo de formación para orientar la formulación y ejecución de una política pública en la materia que se concretó en la década de los cincuenta del siglo XX.

Es así como, durante la década de los años 50, se llevaron a cabo algunos estudios de manera externa4- sobre la enseñanza secundaria costarricense en general, los cuales develaron que no estaba respondiendo al contexto que se vivía en la época; lo que

${ }^{4}$ Unión Panamericana 1953, Dirección General de Asistencia Técnica de la UNESCO. 
propiciaba una pésima y poco atractiva valoración de la misma, que además no demostraba su aporte al desarrollo económico y social del país.

De igual manera, al Ministerio de Educación le inquietaba el rumbo que tomaban las personas jóvenes al abandonar las aulas de los colegios de segunda enseñanza, tanto por quienes no continuaban en ellas, como por la población estudiantil que una vez finalizada la secundaria, no accedía a la educación superior (MEP, 1952).

Según Crespo (1954) la primera inquietud se debía a "[...] el número mayor de muchachos que dejan sus estudios truncos, pues estos no responden a sus capacidades e intereses" (p.8); además de los cuestionamientos acerca de si la juventud apoyaba o no el desarrollo del país, esto al observar modelos educativos de países más desarrollados, donde se evidenciaba que la apuesta por la educación vocacional había dado resultados (Crespo, 1954, p.8).

Ante tales circunstancias se pusieron en práctica acciones encaminadas al establecimiento de centros educativos donde la enseñanza secundaria fuera vocacional, y el fortalecimiento de la formación de personal docente; siguiendo lo señalado por el MEP (1954), después de que el Dr. Marvin S. Pittman -jefe de la Misión de Asistencia Técnica de la UNESCO-, emitiera recomendaciones a estudios de la educación secundaria, mismas que fueron retomadas por el MEP a mediados de la década de 1950.

En este sentido, en 1952 dio inicio un plan piloto de enseñanza vocacional en el Liceo José Joaquín Vargas Calvo, en San Pedro de Montes de Oca. Los resultados obtenidos, dieron paso al establecimiento de una Comisión para Estudios de la educación vocacional que recomendaba la creación de un Sistema Nacional de Educación Vocacional [...] (la comisión) dio algunas recomendaciones para establecerlo entre las que estaban solicitar asistencia técnica de otros países y organismos internacionales" (Rojas, 1977, pp. 37-38), siendo Estados Unidos el principal país a quien se le solicitó cooperación y que se materializó con las estrategias del Punto Cuarto y la Agencia Internacional para el Desarrollo $(\mathrm{AID})^{5}$.

Por tanto, el agotamiento del modelo agroexportador que acompañó las primeras décadas del siglo XX y la transición hacia la industrialización del sector economía, así como la discusión en torno a la necesidad de profesionalizar la mano de obra, posicionaron la

\footnotetext{
${ }^{5}$ Misión de asesoría en Educación Vocacional, que llegó a Costa Rica con el objetivo de reorganizar la educación secundaria, normal y la formación de personal docente, con las competencias para la implementación de la enseñanza vocacional.
} 
Educación Vocacional en la agenda política de las autoridades educativas y políticas como una de las posibles soluciones a la necesidad de dotar al país de los cuadros profesionales y/o técnicos necesarios para su desarrollo económico y social, por lo que mediante la participación en actividades educativas regionales ${ }^{6}$-, el desarrollo de investigaciones y el estudio de las posibilidades de ponerla en práctica en Costa Rica, se gestó una nueva política educativa, esto teniendo en cuenta que según Rojas (1977) "en mil novecientos cincuenta no había en Costa Rica personal preparado en Educación Vocacional (Técnica), con la sola excepción de los padres salesianos [...]" (p. 50).

De igual manera, la influencia extranjera que recibió el país desde que se situó el tema en la agenda nacional, impulsó convenios entre el gobierno de Costa Rica y organismos $^{7}$ como la UNESCO y la OIT, accionar que promovió que en los años siguientes se diera el establecimiento del Instituto Vocacional de Alajuela, ente que en su planificación no solo contemplaba la infraestructura, si no que incluía la preparación de personas en el extranjero, como instructores del centro de enseñanza (MEP, 1952).

Fue en el año 1956 cuando donde se oficializó la Política educativa vocacional, con la aprobación "del primer plan de estudios específico para esta modalidad y se establece el financiamiento estatal de esta actividad educativa, así como su universalización" (PEN, 2011 cp. MEP, 2015, p.9). Además, a nivel administrativo se estableció la Sección Vocacional del MEP, mediante la Ley №1998 del primero de febrero 1956 (Rojas, 1977), lo cual tuvo como consecuencia que en 1959 existieran los primeros tres colegios vocacionales: Monseñor Sanabria -Desamparados-, Heredia y Golfito. En esa primera etapa, la formación se centró en la temática industrial, incluyendo durante los años 60 el tema agropecuario y en los años 70 lo artesanal.

A partir de dicha oficialización se gestaron algunas transformaciones en materia educativa significativas para la época: en 1961 se creó el Reglamento para Colegios Vocacionales el cual plasmó el marco filosófico y la intencionalidad con la que se estructuró la Educación Vocacional y posteriormente la Educación Técnica Profesional a lo largo de la década de los años 60 , tomando como referencia el concepto recomendado en el Seminario

\footnotetext{
6 "Primera Conferencia Regional de Comisiones Nacionales del Hemisferio Occidental" (Crespo, 1954), Primer Seminario Centroamericano de Educación Vocacional y Técnica celebrado en Guatemala en 1957 (Ministerio de Educación Pública de Guatemala, 1958, p.7).

7 También destaca la participación de la Misión Punto Cuatro, (AID), OEA -Sección de Educación Vocacional-, Misión Punto Cuatro, (AID) y Sección Educación Vocacional de la Unión Panamericana; las cuales participaron en la reorganización de educación secundaria, normal y la formación de personal docente, cooperación técnica, investigaciones, e implementación de la Educación Vocacional y Técnica en Costa Rica, según de se detalla en las memorias del Ministerio de Educación Pública (1950-1959).
} 
Centroamericano de Educación Vocacional y Técnica de 1957 -con unos ligeros cambios en la redacción- tal y como lo señalaba el artículo 1:

(...) la Educación vocacional es una modalidad de la enseñanza media, que se ofrece a los adolescentes con el propósito de ayudar a desenvolver en forma específica sus preferencias vocacionales. Se considera un proceso educativo que forma integralmente al individuo para el ejercicio de un oficio, arte u ocupación que le permita participar inteligentemente en la vida, satisfacer con dignidad sus necesidades personales y familiares, y contribuir al progreso de la sociedad. (MEP, 1961, p.1)

De lo anterior se desprendía una modalidad de educación restringida a la población adolescente, con la pretensión de una formación personal integral que posibilitara educar para el trabajo ya que como es indicado en el artículo 2, las entidades encargadas de la modalidad -llamadas Colegios Vocacionales oficiales- "son instituciones pertenecientes al sistema escolar costarricense destinado a la formación de peritos en aquellos oficios, artes y ocupaciones que demanda el país" (MEP, 1961, p.1).

Además, se crearon los Institutos Agropecuarios, que surgieron de la necesidad de crear un nuevo tipo de Colegio Vocacional con el fin de suplir la necesidad de personal capacitado en el área agrícola y "de resolver el problema de un enorme sector de jóvenes cuyo destino no debía y ni podía ser el Bachillerato; el que pudiéramos preparar más bien para el progreso de su propia comunidad y dotarlo de conocimientos básicos y fundamentales en el campo del trabajo [...]" (MEP, 1962, p. 11).

A partir de lo anterior, y con el "asesoramiento del A.I.D.U.S.A. determinamos un tipo de colegio vocacional que llamamos "Instituto Agropecuario" en donde los jóvenes reciben además de las asignaturas fundamentales del primer ciclo de enseñanza media conocimientos prácticos de agricultura, de ganadería, artes industriales y de educación para el hogar" (MEP, 1962, p. 11). Así se amplió la oferta educativa a nivel vocacional con la existencia de dos tipos de colegios en dos grandes ramas a saber; la Industrial y la Agropecuaria, aunque con la limitante de que no fueron de acceso a toda la población estudiantil pues los primeros se ubicaban principalmente en el área urbana (Heredia, Desamparados) y los segundos en zonas rurales (Abangares, Palmar Norte).

En ese mismo año, a nivel ministerial, se pasó de tener una sección vocacional a inspección general. Misma que volvió cambiar en su nomenclatura y funciones varias veces, 
hasta llegar a lo que conoce hoy día, tal y como se puede observar en la figura 1 (que irá siendo retomada a lo largo del documento).

Figura 1. Transformación en nomenclatura y funciones de la Educación Técnica en el Ministerio de Educación Pública 1956-2007

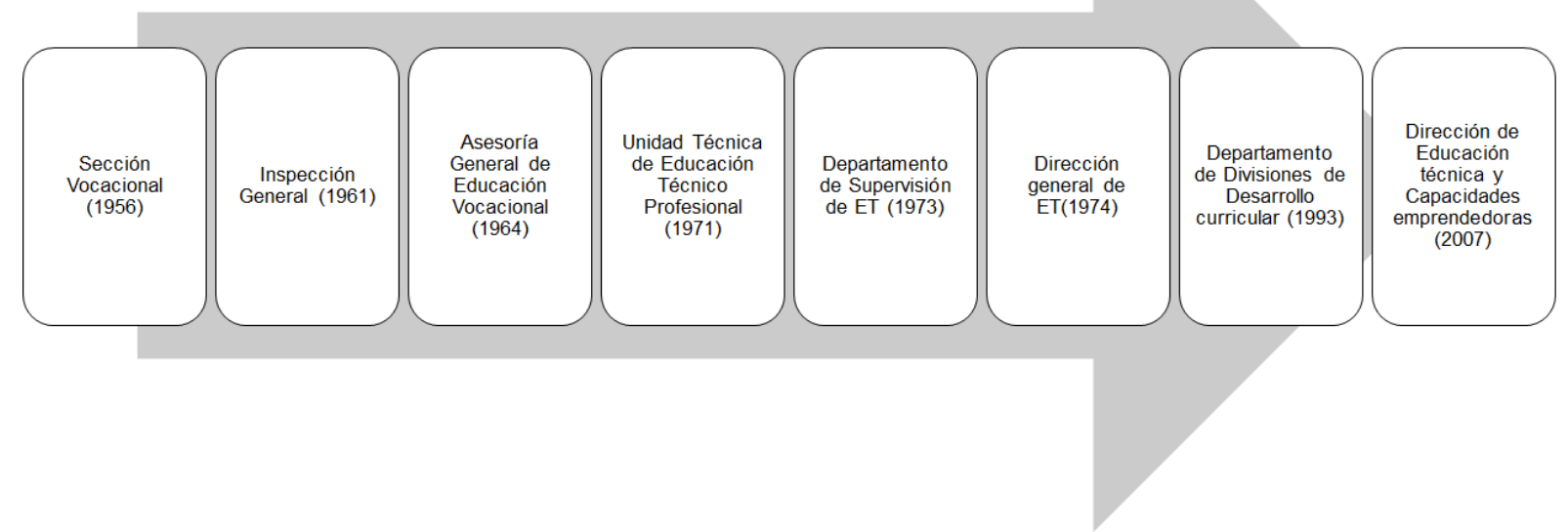

Fuente: Alvarado, Gabriela; Araya, Juan José; Elizondo, Deiner; Hidalgo, Pamela; Mora, Raquel, Peralta, Jeimy. (2016).

Durante 1963 se planteó una reforma a la enseñanza media, que inició con un proyecto de un plan de estudios basado en ofrecer mediante "[...] un ciclo de enseñanza secundaria común, igual para todos los adolescentes, varias modalidades diversificadas que comprenderían el segundo ciclo" (MEP, 1962, p.137) y además, "se pensó en otorgar, al término de los cinco años de estudios, varios títulos de Bachiller, según los planes elaborados o escogidos por los propios alumnos: Bachillerato en Letras, en Ciencias y en materias vocacionales." (MEP, 1962, p.137-138).

Ahora bien, en 1964 se ejecutó la reforma y en relación a la Educación Vocacional planteó las siguientes acciones: unificación de los programas académicos, se crearon programas vocacionales agropecuarios, como programas anexos en los Liceos de Puriscal, San Isidro de El General y Santa Cruz de Guanacaste. Se presentaron al Consejo Superior de Educación (CSE) programas para Educación para el hogar y Artes Industriales, así como los Institutos Agropecuarios, para definir el futuro de los peritos agrícolas. Además, se presentó un plan de reestructuración de la Educación Vocacional para su estudio y 
soluciones para equiparar a las personas graduadas de modalidades vocacionales, con el nivel y las mismas oportunidades que tenían los bachilleres en Ciencias y Letras para ingresar a cursos superiores (MEP, 1965 p.197).

Para este año la inspección cambió nuevamente de nombre, pasando a ser Asesoría general de Educación Vocacional. Que en 1966 pasó de ser Educación vocacional a Educación Técnica (de acuerdo al plan de estudio) y de Sección Vocacional a sección profesional, con bachillerato profesional en Industrial, Comercial y Agropecuaria. Para el año 1969, se llevó a cabo la modificación y separación de los títulos para Perito y para Bachiller profesional, "[...] pudiéndose obtener cualquiera de los dos independientemente" (Rojas, 1977, p.18.).

Durante la época de los años 70, se estableció el Plan Nacional de Desarrollo Educativo, puesto en práctica entre 1971 a 1975 y de 1976 a 1980, el cual se caracterizó como "la gran proposición que se plantea para mejorar progresivamente la educación nacional" (MEP, 1970). Iba dirigido a la mejora de la eficacia interna y externa del sistema, abaratando sus costos, y sobre todo poniéndolo realmente al servicio del desarrollo nacional (MEP, 1970). En el mismo se menciona el cambio de la Educación Vocacional a Técnica y se estipula que las personas egresadas en Educación Técnica estarán capacitadas para las siguientes funciones:

(...) operar y mantener medios de producción y servicios de tecnología avanzada, incluyendo la dirección de los obreros calificados y no calificados [...] Establecer algunas empresas independientes [...] Prestar servicios auxiliares a profesionales de nivel superior (MEP, 1970).

Aunado a esto, se estableció que la Educación Técnica se dividiría en las siguientes ramas, Industrial, Comercial, Agropecuaria, Comunicación, Sanidad y Artesanía (MEP, 1970). El MEP (1976) además, mencionaba que se había logrado "la creación de dos instituciones especializadas: una para la capacitación de los profesores de la Educación Técnica y otra para los profesores de la Educación Científica" (s.p).

Se debe destacar además que para el año 1978, se dio un cambio importante en materia de reconocimiento del grado académico de las personas egresadas y graduadas de Educación Técnica, el CSE "definió oficialmente el grado técnico a nivel medio para los estudiantes graduados que culminaran la especialidad técnica. Previo a este hecho, los estudiantes egresaban con el título de "perito", situación que permitió la ampliación del 
currículum y el reconocimiento de los graduados para efectos salariales" (Programa Estado de la Nación, 2011 c.p MEP, 2015, p.11).

Hubo también cambios importantes en la nomenclatura de la entidad rectora en el tema de la Educación Técnica, que tuvieron consecuencias en las tareas y metas a desarrollar:

- Cambio a Unidad Técnica de educación Técnico-profesional (1971): las labores de supervisión recayeron en "una sola persona, el Asesor General de Educación Profesional, quien por primera vez desde la creación del Sub-Sistema no controla todos los aspectos de Supervisión y Asesoramiento del Sub-Sistema” (Rojas, 1977, p.46). En este sentido, se puede señalar un retroceso en lo que respecta a la estructura organizativa de la modalidad en estudio, al pasar de la figura de Asesoría General de Educación Vocacional establecida en 1964, a una Unidad Técnica de Educación Técnico- Profesional, a la cual se le diluyó la función de asesorar al subsistema y se le supeditó en su totalidad al desempeño de "trabajos" que el Departamento de Currículum considerara necesarios.

- Creación del Departamento de Supervisión Técnica (1973): que tendría a su cargo "la atención de aquellos aspectos concernientes a los establecimientos de III Ciclo y Educación Diversificada de la Rama Técnica (MEP, 1973, p.328).

- Cambio a Dirección General de Educación Técnica (1974): se realizó un análisis de la Educación Técnica en un marco general de análisis de lo logrado hasta el momento con el Plan Nacional de Desarrollo Educativo, en el cual se detectaron importantes problemas en lo que se refería al área Agropecuaria; se desarrollaba en escuelas, centros comunales y hasta en iglesias por falta de edificios apropiados, no contaba con terrenos suficientes para las prácticas, laboratorios y herramientas. Ante ello, las autoridades educativas además de tomar medidas para la dotación de recursos a los Institutos Agropecuarios, para mejorar la situación optaron por elevar la condición del Dirección General el Departamento de Educación Técnica (MEP, 1974).

- Creación de las Unidades Técnicas específicas por rama técnica (1976): cuya tarea fundamental era cumplir acciones de supervisión y asesoramiento de acuerdo a la temática correspondiente.

Estos cambios operaron en razón de la designación de la labor de ejecución de la política, estando ésta ligada a las funciones de asesoría y supervisión; lo que implicó que 
desde el subsistema de Educación Técnica se perdiera dicha potestad y hasta 1976 retomara la supervisión y el asesoramiento de la Educación Técnica Profesional en todo el país, en forma directa.

Sumado a ello, la inversión realizada por el Banco Interamericano de Desarrollo (BID), específica para equipamiento e infraestructura, llegó en un momento en que la infraestructura con la que contaban los Colegios Técnicos carecía de equipo y de comodidades físicas mínimas (MEP, 1970). Las inversiones realizadas en materia económica, permitieron que en esta década se crearan alrededor de 53 Colegios Técnicos en diferentes partes del país (Programa Estado de la Nación, 2011 c.p. MEP, 2015, p.11).

No deja de ser importante, la creación de la Comisión Nacional de Coordinación de la Educación Técnica, entre el MEP, el Instituto Nacional de Aprendizaje (INA) y el Instituto Tecnológico de CR (ITCR), en 1979, con la finalidad de crear proyectos cooperativos entre dichas instancias (MEP, 1978).

En la década de los 80, el país atravesó una crisis económica fuerte, que llevó a tomar decisiones dicha materia, entre ellas la aplicación de los Planes de Ajuste Estructural (PAEs). La crisis mencionada, tuvo un impacto directo en el tema educativo, ya que durante el periodo comprendido, hubo un estancamiento importante.

Sin embargo, fue posible identificar que durante 1981 se dio la Regionalización de la Educación Secundaria - que tenía la finalidad de desconcentrar las funciones y poder avanzar en cuanto a la planificación, ejecución y evaluación de programas, proyectos servicios y actividades- e implicó mayor cobertura y alianzas estratégicas, que permitió brindar mayores condiciones de accesibilidad para estudiantes; dando especial importancia a la figura del cuerpo docente y su proceso de formación y capacitación "debe responder con agilidad y con amplitud humanística con profundidad en sustento a axiológico y con rigor técnico a los imperativos de una educación como la que se ha descrito" (MEP, 1982, p.12).

Pese a ello, en 1983, hubo que hacer -como respuesta ante la crisis- una readecuación de las especialidades técnicas, ejemplo de ello es que durante esta administración no se llevó a cabo el establecimiento de ningún nuevo Colegio Técnico Profesional según refiere el Departamento de Estudios e Investigación Educativa (2014). Todo ello, tuvo como consecuencia, que para 1988 se evidenciara un debilitamiento de los colegios técnicos, que fueron "desplazados" por los colegios científicos y tecnológicos,

(...) es en este sentido que se inicia una transformación cualitativa de la Educación

Técnica del país. [...] Aun así el esfuerzo ha sido extraordinario en función de una 
conceptualización distinta, en que se conjugan en la práctica los conceptos Educación -Trabajo-Producción y la introducción de principios científicos y tecnológicos. (MEP, 1990, p.127)

Los primeros años de la década de los noventa se vieron marcados, entre otras cosas, por la repetición de algunas problemáticas ya conocidas como por ejemplo: la exclusión, las altas tasas de deserción, el desgranamiento y la repitencia de jóvenes estudiantes, además de salarios docentes históricamente deprimidos, una formación y un régimen laboral docente que se consideraban permitidos en un contexto de baja prioridad de las inversiones en educación; mal aprovechamiento de los ya escasos recursos disponibles, y propuestas de enseñanza atrasadas y desgastadas.

Ante ello, surgió la necesidad de reformar las propuestas, que requería analizar la pertinencia y concordancia de la formación con respecto a los cambios contextuales que iban surgiendo; la creación de nuevos planes de estudio que dieran respuesta a las demandas de las poblaciones involucradas, actualizar y capacitar al personal para hacer frente a las restricciones presupuestarias producto de la crisis; y el establecimiento de alianzas nacionales e internacionales que permitieran ahondar en las modificaciones necesarias ante el panorama que se presentaba.

En 1993 se dio, por un lado, una reestructuración de las Oficinas centrales del MEP, que derivó en la consolidación del Departamento de Divisiones de Desarrollo Curricular, que llegó a sustituir la figura de la Dirección General de Educación Técnica. Por el otro lado, se creó la Ley 7372, que clarificaba los mecanismos de financiamiento de la Educación Técnica, estableciendo que los recursos provendrían del superávit anual del INA y definía claramente los porcentajes que debían ser asignados según diversas características como ubicación geográfica de los Colegios Técnicos o según las especialidades impartidas en cada uno de ellos (Asamblea Legislativa, 1993, Art. 2-3-4-5).

Un año después, bajo la administración ministerial de Eduardo Doryan Garrón, se instauró la Política Educativa "Hacia el siglo XXI", en sus planteamientos iniciales, la educación era entendida como un derecho de la población, amparada en un marco jurídico que resalta la Constitución Política y Ley Fundamental de Educación; que se desarrolla de manera paralela a la comprensión de la población estudiantil como sujetas y sujetos activos y participativos del proceso educativo. Fue sustentada en dos pilares; el acogimiento por parte del sistema educativo de una visión integral del ser humano, en aras de contribuir al 
desarrollo integral de la persona y la sociedad, así como, la coexistencia de una coherencia entre teoría y práctica, pues de lo contrario, se tiende a desarticular y por ende, reducir la calidad del proceso ofrecido a la población estudiantil (Consejo Superior de Educación, 1994). Fue nutrida además por fuentes filosóficas, constituida por las siguientes visiones:

- Humanista: este elemento constituye el 'para qué se aprende', en tanto se plantea la importancia de comprender a las personas como seres con dignidad, valor, capacidad y toma de consciencia de la realidad en que se desenvuelven.

- Racionalista: constituye el 'qué se aprende', visualizando al ser humano dotado de una capacidad racional, que le permite estar en constante construcción y perfeccionamiento del conocimiento.

- Constructivista: establece el 'cómo se aprende', considera pertinente que el proceso educativo parta de la situación cognoscitiva del o la estudiante, reconociendo la cultura e individualidad de cada persona con sus respectivas estructuras de conocimiento (Consejo Superior de Educación, 1994).

Como parte de sus objetivos se planteó "fortalecer la educación técnica y científica, a la par de la deportiva y la cultura; como forma de estimular el desarrollo integral de los estudiantes" (MEP, sitio oficial). En este tema, si bien es cierto que no hubo una especificación de la estrategia para su fortalecimiento, en el periodo comprendido entre mayo de 1996 y marzo de 1997, el gobierno propició una serie de acciones orientadas hacia su mejoramiento en pro del beneficio de los más de 40.000 estudiantes que atendía en dicho momento. De igual manera, se pretendía promover la formación del recurso humano de nivel medio requerido por el sector productivo nacional, la pequeña y mediana empresa moderna e impulsar el desarrollo de empresas de alta tecnología con el fin de enfrentar con éxito el proceso de globalización y la competitividad que ello originaba (MEP, 1997).

Para 1998, se creó el Sistema Integrado Nacional de Educación Técnica para la Competitividad (SINETEC), que incluía al MEP, al ITCR y al INA, pero que no pudo ser concretado, hecho que derivó en que las acciones desarrolladas a favor de la Educación Técnica, siguieran estando desarticuladas y separadas del sector productivo.

En el año 2000, se aprobó la Ley de creación e integración de la Comisión Nacional de Fomento de la Educación y la Formación Dual, que tenía como fin la utilización de la 
formación dual en los procesos de enseñanza-aprendizaje de para estudiantes de secundaria ${ }^{8}$.

Se reformó en el año 2001 el SINETEC que había sido creado en el año 1998. E objetivo de la reforma consistió en re-definir las funciones que debían asumir tanto el Consejo de la entidad, así como la Comisión Técnica respectiva. De igual manera, especificó que a partir de ese año debería asignarse el presupuesto correspondiente, elaborado por el Presidente del Consejo mencionado según lo establecido en los artículos del uno al tres (Asamblea Legislativa, 2001, s.p).

Con el cambio de administración ministerial, bajo el mando de Leonardo Garnier Rímolo, se propuso en 2006, el Modelo de Educación basado en las Normas por Competencias Laborales (EBNC) -que se había planteado en la década anterior- ${ }^{9}$, así como la puesta en práctica de las 10 líneas estratégicas del MEP -para efectos de este artículo, se hace mención específica a la que propicia la capacidad productiva de las personas jóvenes (adolescentes, jóvenes y jóvenes adultos) a través del desarrollo de competencias para el trabajo, los idiomas y los aspectos tecnológicos y de comunicación.

(...) el MEP viene realizando esfuerzos sistemáticos por actualizar y modernizar los programas de los colegios técnicos, incorporando nuevas especialidades más acordes con lo que el futuro parece exigir de las nuevas generaciones de trabajadores; fortaleciendo el aprendizaje de un segundo y tercer idioma en los distintos niveles y modalidades del sistema educativo, promoviendo una cultura 'emprendedora' centrada en la resolución de problemas más que en la perpetuación de rutinas y -por supuestoapoyando la capacitación permanente de los docentes para poder enfrentar en forma adecuada estos retos. (MEP, 2008, p.9-10)

\footnotetext{
${ }^{8}$ La Educación Dual es una modalidad que combina la enseñanza sistemática en un centro de formación con la aplicación inmediata de los conocimientos adquiridos en una empresa [...], ofrece la oportunidad de unir los esfuerzos y recursos de los centros educativos con los de las empresas del sector productivo [...], puede aumentar la capacidad de los centros educativos, aprovechando del potencial de puestos de aprendizaje dentro del sector productivo [...] (Asamblea Legislativa, 2000, s.p).

${ }^{9}$ [1] El modelo de Educación Basado en Normas de Competencia es una modalidad educativa que promueve el desarrollo integral y armónico del individuo y le capacita en las competencias que requiere una actividad productiva específica. Así, por un lado, se atienden las necesidades del sujeto y por otro los requerimientos de los sectores productivos, "[...] la formación para el trabajo busca desarrollar los atributos del sujeto para aplicarlos de manera óptima e inteligente en las tareas de su ocupación laboral y permite la transferencia de las competencias a diferentes contextos y situaciones de trabajo" (MEP, 2008, p.41).
} 
Una nueva reforma educativa (en 2007), dio paso a la transformación del Departamento de ET a la Dirección de Educación Técnica y Capacidades Emprendedoras (DETCE), concebida como la instancia técnica encargada de

(...) analizar, estudiar, formular, planificar, asesorar, investigar, evaluar y divulgar todos los aspectos relacionados con la educación técnica profesional en Tercer Ciclo y Educación Diversificada, así como promover programas y proyectos para potenciar su vinculación con los mercados laborales [...] la educación técnica, además de tener una dinámica propia que debe ser consistente con las necesidades de las distintas regiones, constituye un medio para promover una educación útil y pertinente, que contribuya a reducir la marcada deserción que se registra en secundaria. Su funcionamiento interno supone la articulación de tres departamentos: Educación Técnica, Gestión de Empresas y Educación Cooperativa y Vinculación con la Empresa y la Comunidad [...]" (MEP, 2008, p. 71).

De igual manera, en el mismo año, se creó la figura de los Consejos Regionales de Vinculación con la Empresa y la Comunidad (CORVEC), enfocados en las consultas al sector productivo y la identificación de posibles cambios a los contenidos de los programas de estudio de las especialidades y variaciones en el perfil de los técnicos medios, "[...] las opiniones obtenidas permiten la actualización de la oferta educativa, para que responda eficazmente a los requerimientos del mercado laboral y potencie la inserción laboral de los graduados [....]" (MEP, 2014, p. 286).

En el 2010, pese al cambio de administración gubernamental, se contó nuevamente con el señor Garnier al frente del MEP, lo que produjo que se crearan y mantuvieran buenas prácticas educativas; entre ellas, el aumento considerable de opciones técnicas y vocacionales, a través de la transformación de liceos académicos en Colegios Técnicos y la creación de las secciones técnicas nocturnas.

En la administración 2010-2014 se abrieron 117 alternativas vocacionales (que incluían las opciones diurna, nocturna, Plan a Dos años). La matrícula aumentó en casi 50\%, para un total aproximado de 95000 estudiantes (MEP, 2014, p.264). De esas alternativas, 27 fueron transformaciones de colegios académicos a técnicos (MEP, 2014, p.269). A finales del año 2014, se contaba entonces, en la modalidad técnica, con: 133 CTP diurnos y 85 secciones nocturnas (MEP, 2015b, s/p), sumados a los 12 colegios con la opción "Plan a Dos Años", el CINDEA y los 7 Institutos Profesionales de Educación Comunitaria. De 135 CTP, sólo 108 
ofrecen III ciclo y Educación Diversificada, los otros 25 sólo ofrecen Educación diversificada $\left(10^{\circ}, 11^{\circ}\right.$ y $\left.12^{\circ}\right)$ (MEP, 2015, p.18). Dichos centros educativos ofrecen especialidades en las áreas de comercio y servicios, agropecuaria e industrial (Ministerio de Educación Pública, 2006-2014, p.283).

Además, en 2010 se empezó a desarrollar un Encuentro Anual de Líderes estudiantiles de Educación Técnica, que reúnen a representantes de todos los colegios técnicos del país, para discutir temáticas de importancia, así como brindar herramientas para mejorar la convivencia en el centro educativo.

En términos generales sobre el contexto educativo, en la última década mencionada, aparecieron propuestas importantes para la defensa de los intereses estudiantiles, con la creación de la Oficina de los Derechos de la Niñez y adolescencia, que posteriormente se convirtió (en 2014) en la Contraloría de derechos estudiantiles, cuyo fin primordial era

(...) desarrollar un sistema de protección y respeto de los derechos y deberes estudiantiles, de conformidad con el ordenamiento jurídico. Le corresponde controlar y fiscalizar que la población estudiantil reciba una educación orientada al desarrollo pleno de sus potencialidades, orientada por el interés superior de los niños, las niñas y adolescentes, velando por el respeto de sus derechos y el cumplimiento de sus deberes en un ambiente físico y mental sano [...]. (MEP, 2014)

Con las últimas reformas a la organización administrativa del MEP, se creó la Dirección de Vida Estudiantil, cuyas funciones -según el último decreto el 38170, del año 2014-, se orientaron a la conversión de este ente como el espacio responsable de dar voz a la comunidad estudiantil, a través de los diferentes programas que administran, a saber:

(...) Gobiernos Estudiantiles y Servicio Comunal Estudiantil -del departamento de Participación Estudiantil-, Bandera Azul Ecológica y Juegos Deportivos Nacionales -del departamento de Salud y Ambiente-, Festival Estudiantil de las Artes y Convivir- del departamento de Convivencia Estudiantil- y aquellos proyectos específicos para el departamento de Orientación y Educativa y Vocacional. (MEP, 2014)

\section{Conclusiones}

A raíz de lo expuesto en páginas anteriores, es posible identificar como la Educación Técnica, como modalidad de estudio propuesta por el MEP, se encuentra en constante (re) construcción, al ajustarse a las necesidades del desarrollo nacional, procurando vincular a 
los sectores productivos y coordinar las diversas instancias con ella relacionada. Desde la perspectiva sistémica, podría entenderse que las fases no están acabadas y lo que en primer momento se consideraron "salidas", pueden regresar en forma de "entradas", realimentando los procesos internos de la política misma.

Es posible entender cómo el entorno influye y reconstruye lo que se ha reconocido como el subsistema de Educación Técnica, y éste a su vez modifica el contexto, comprender cada uno de los eventos históricos retratados, no como hechos aislados sin consecuencias, sino como inmersos en una relación de causa-efecto, que determina y afecta -positiva y negativamente- en los posteriores pasos de la política.

Pese a los esfuerzos realizados, también es posible identificar que:

- La capacidad de respuesta del MEP no resulta suficiente ante las demandas del mercado, así como las ofertas que el mismo mercado ofrece para los egresados de Educación Técnica.

- Las coyunturas económicas y políticas gubernamentales que imperaron en los diversos periodos estudiados, determinaron en gran medida los lineamientos políticos y matices que tomó la Educación Vocacional y o Técnica Profesional. Siendo así que las situaciones que se fueron presentando a nivel nacional e internacional, tuvieron consecuencias directas en el mejoramiento o deterioro de las condiciones en que se desarrolló la política como tal.

- Los cambios de administración gubernamental y de personal político a cargo del tema, influyen en que no haya una continuidad de propuestas, que haya retrocesos significativos en el desarrollo de estrategias y programas acordes al contexto y las características propias de la zona en la que se encuentran los centros educativos. Sumado a ello, los compromisos políticos asumidos por las autoridades, con diferentes instancias internacionales, influyen considerablemente en la definición de la política y sus planes de ejecución.

- A pesar de que el discurso que se maneja sobre la Educación Técnica y sus fines se enfoca en la inserción o garantía al ámbito laboral como preámbulo para alcanzar movilidad social, se considera que la modalidad de estudio se convierte en una aproximación a este espacio más que una garantía, máxime que en determinados momentos las tasas de desempleo dan cuenta de que el mercado es incapaz de absorber toda la mano de obra que se forma. 
- La utilización del modelo posibilitó el análisis de los productos de la acción estatal en materia de Educación Vocacional y Técnica Profesional y relacionarlos con el complejo mundo de acciones e interacciones entre actores sociales, intereses públicos y privados así como con su población objetivo, al estudiar a fondo la política, determinar su impacto sobre la realidad y como resultado final, como output o producto del sistema educativo (la Educación Vocacional y Técnica Profesional como un medio efectivo para formar mano de obra calificada para el país).

- La utilización la teoría General de Sistemas, permitió la comprensión de la política como un sub-sistema en el que los elementos están correlacionados directamente y que forman subsistemas individuales, que pueden afectarse entre sí y por tanto afectar al contexto en general. De igual manera, posibilitó el estudio por separado de cada una de las categorías de análisis, paralelo al análisis de todas ellas interrelacionadas, formando un todo. Visto desde dicha teoría, identificar entradas y salidas en el curso del análisis de la política posibilitó visualizar y comprender los procesos internos resultantes de la interacción entre ellas y develar las transformaciones de la política como tal, entendiendo que los procesos de política pública no se encuentran estancados ni sin posibilidades de cambio. Por el contrario, la combinación de todos los factores permite la interrelación estrecha entre ellos, y reconoce que cada uno de éstos influye directamente sobre el otro y le determina, al igual que lo hace a partir y desde el entorno en que se desenvuelve.

\section{Recomendaciones}

- Realizar una actualización constante de los fines y objetivos de la Educación Técnica Profesional en función de las necesidades presentes y con una visión futurista, en razón de que pueda dar respuesta a la celeridad de los cambios tecnológicos que repercuten en los aspectos económicos, sociales, políticos e incluso culturales de la sociedad costarricense.

- Analizar el funcionamiento de la estructura administrativa y el marco jurídico al que está sometida la Educación Técnica, de manera que cuente con una estructura ágil y funcional, autónoma e independiente en el desempeño de sus funciones, que evite que la modalidad sea supeditada a otras estructuras dentro del MEP que limiten su crecimiento como ocurrió en décadas pasadas. 
- Incorporar a la población estudiantil, como un actor más en los procesos de vinculación, asesoría, consulta y toma de decisiones que se realizan a nivel de CORVEC. De manera que se garantice el derecho a la participación, como requisito para lograr trabajos inter-sectoriales que tomen en cuenta las necesidades, expectativas y posibilidades particulares de los grupos de estudiantes y no se reduzcan a meros transmisores de la información obtenida en los Encuentros de Líderes Estudiantiles.

- La vinculación permanente de profesionales del área social en los CTP con la finalidad de identificar las necesidades sociales presentes en la zona geográfica en la que se ubica la institución, en busca de llevar a cabo una mayor articulación entre lo social y lo económico, procurando que la formación de técnicos en determinadas especialidades responda a necesidades en ambos aspectos, partiendo de lo planteado a nivel geográfico y sectores empleadores.

- Orientar los esfuerzos políticos a lograr una mayor coherencia entre lo estipulado en la agenda política de cada gobierno con la realidad del país en torno a las necesidades de la Educación Técnica; es necesario que antes de abrir más centros técnicos de educación secundaria se pongan en orden los ya existentes, brindándoles equipos modernos, herramientas de calidad, adecuado presupuesto, insumos necesarios y personal docente capacitado para que el estudiantado realmente posean una adecuada formación técnica y se conviertan en personal competitivo dentro del mercado laboral.

- Se debe demandar la revisión y evaluación de la Educación Técnica costarricense apuntando a la mejora de los procesos educativos que se desarrollan, en procura de una educación de calidad que retome las necesidades del estudiantado más allá de las demandas del mercado laboral que aspira a mano de obra de bajo costo.

- Inclusión de la Educación Técnica en la agenda prioritaria del Estado, de manera que se superen las propuestas gubernamentales (Planes Nacionales de Desarrollo) que se plantean por periodos cortos de 4 años que impiden dar continuidad a los procesos.

- Realizar un estudio que analice la experiencia de la comunidad y empresa privada/pública a raíz de la Educación Técnica, para así conocer el impacto que esta ha tenido. 
- Analizar a profundidad, las condiciones de trabajo y desarrollo de capacidades a las que se enfrentan quienes egresan de la Educación Técnica, tema no estudiado hasta el momento, puesto que se ha dado especial atención a lo referente a la inserción laboral y las demandas del mercado de trabajo.

- Estudiar el proyecto de Educación Dual presentado en Asamblea Legislativa, buscando identificar las consecuencias tanto para estudiantes como para entidades administrativas, empresas y sociedad costarricense de los planteamientos que de él se derivan.

\section{Referencias}

Alvarado, Gabriela., Araya, Juan José., Elizondo, Deiner., Mora, Raquel., Solano, Pamela. y Peralta, Jeimy. (2016). Educación Técnica secundaria pública en Costa Rica: 19502014 (Memoria de seminario de graduación para optar por el grado de Licenciatura en Trabajo Social). Universidad de Costa Rica, San José, Costa Rica.

Asamblea Legislativa. (1993). Ley para Financiamiento y Desarrollo de Educación Técnica Profesional. Recuperado de http://www.pgrweb.go.cr/scii/Busqueda/Normativa/Normas/nrm texto completo.aspx?p aram1=NRTC\&nValor1=1\&nValor2=22489\&nValor3=0\&strTipM=TC

Asamblea Legislativa de Costa Rica. (2000). Creación e Integración de la Comisión Nacional Fomento de la Educación y la Formación Dual N²9079-MEP. Recuperado de http://www.pgrweb.go.cr/scij/Busqueda/Normativa/Normas/nrm texto completo.aspx?p aram1=NRTC\&nValor1=1\&nValor2=66893\&nValor3=78954\&param2=2\&strTipM=TC\&I Resultado $=18 \& \operatorname{str} \operatorname{Sim}=\operatorname{simp}$

Asamblea Legislativa de Costa Rica. (2001). Reforma el Sistema Integrado Nacional de Educación Técnica para la Competitividad (SINETEC). N²9425-MEP. Recuperado de http://www.pgrweb.go.cr/scij/Busqueda/Normativa/Normas/nrm texto completo.aspx?p aram1=NRTC\&nValor1=1\&nValor2=46233\&nValor3=48789\&param2=3\&strTipM=TC\&l $\underline{\text { Resultado }=30 \& \operatorname{strSim}=\operatorname{simp}}$

Baptista, Pilar., Fernández, Carlos. y Hernández, Roberto (2010). Metodología de la investigación. México: McGRAW-HILL / INTERAMERICANA EDITORES, S.A. DE C.V.

Calderón, Indra. (2015). Importancia de Fomentar la Educación Técnica en Costa Rica. San José, Costa Rica. Recuperado de: http://www.elmundo.cr/opinion/importancia-defomentar-la-educacion-tecnica-en-costa-rica/

Cartera de Instrucción Pública. (1905). Memoria de Instrucción Pública. Recuperado de: http://mep.janium.net/janium-bin/detalle.pl?ld=20160313055413

Cartera de Instrucción Pública. (1906). Memoria de Instrucción Pública. Recuperado de: http://mep.janium.net/janium-bin/detalle.pl?ld=20160313055413 
Consejo Superior de Educación. (1994). Política Educativa Hacia el Siglo XXI. San José, Costa Rica. Recuperado de: http://www.oei.org.co/quipu/costrica/

Cordero, Wálter. y Leal, Luis. (1987). La formación de técnicos en la educación técnica agropecuaria, en la región Huetar Atlántica, lineamientos y estrategias curriculares (Tesis para optar por el grado de Licenciatura en Ciencias de la Educación con énfasis en Currículum). Universidad de Costa Rica, Sede Rodrigo Facio.

Cox, Maricel. (2005). Fortalecimiento de la Educación Técnica en Costa Rica (Diseño de Investigación como requisito parcial para optar al grado de Magíster en Evaluación de Proyectos y programas de desarrollo). Universidad de Costa Rica, Sede Rodrigo Facio.

Crespo, Ana. (1954) Educación pre-vocacional y Educación Vocacional o profesional en Costa Rica (Tesis para optar por el grado de Licenciatura en Filosofia y Letras) Universidad de Costa Rica, Sede Rodrigo Facio.

Departamento de estudios de investigación educativa. (2014). Establecimiento Cronológico de los colegios técnicos profesionales. San José, Costa Rica.

Hinojosa, Miriam., Larrue, Corinne., Knoepfel, Peter. y Varonne, Frederic. (Enero-junio, 2007). Hacia un modelo de análisis de políticas públicas operativo. Un enfoque basado en los actores, sus recursos y las instituciones. Ciencia Política, (3), 6-29. Recuperado de: http://dialnet.unirioja.es/servlet/articulo?codigo=3663617

lamamoto, Marilda (2003). El Servicio Social en la contemporaneidad, Trabajo y formación profesional. Sao Paulo, Brasil: Cortez Editora.

Ishizaka, Hiroki. (2011). Introducción de Estudio de Política Educativa para Analizar Casos Concretos. San José, Costa Rica: litografía e imprenta LIL.

Johansen, Osear. (1981). Introducción a la Teoría general de sistemas. México: Limusa

López, Xinia., Víquez, Enrique., Ávila, Gerardo. (2001). Educación Técnica y Formación Profesional en Costa Rica. San José, Costa Rica: INA, SINETEC.

Luhamann, Niklas. (1984) Sistemas Sociales. Lineamientos para una teoría general. Barcelona, España: Anthropos Editorial.

Ministerio de Educación Pública. (1951). Memoria anual de labores 1951. Recuperado de http://mep.janium.net/janium-bin/detalle.pl?ld=20150830165557.

Ministerio de Educación Pública. (1952). Memoria anual de labores 1951. Recuperado de: http://mep.janium.net/janium/MEP/memorias.html

Ministerio de Educación Pública. (1954). Memoria anual de labores 1953. Recuperado de: http://mep.janium.net/janium/MEP/memorias.html

Ministerio de Educación Pública. (1961). Reglamento para los Colegios Vocacionales. San José, Costa Rica: Asesoría General de Educación Vocacional. 
Ministerio de Educación Pública. (1962). Memoria anual de labores 1961. Recuperado de: http://mep.janium.net/janium/MEP/memorias.html.

Ministerio de Educación Pública. (1965). Memoria anual de labores 1964. Recuperado de: http://mep.janium.net/janium/MEP/memorias.html.

Ministerio de Educación Pública. (1970). Memoria anual de labores 1969. Recuperado de: http://mep.janium.net/janium/MEP/memorias.html.

Ministerio de Educación Pública. (1971). Memoria anual de labores 1970-1971. Recuperado de: http://mep.janium.net/janium/MEP/memorias.html

Ministerio de Educación Pública. (1973). Memoria anual de labores 1972. Recuperado de: http://mep.janium.net/janium/MEP/memorias.html.

Ministerio de Educación Pública. (1974). Memoria anual de labores 1973. Recuperado de: http://mep.janium.net/janium/MEP/memorias.html.

Ministerio de Educación Pública. (1976). Memoria anual de labores 1975. Recuperado de: http://mep.janium.net/janium/MEP/memorias.html.

Ministerio de Educación Pública. (1977). Memoria anual de labores 1976. Recuperado de: http://mep.janium.net/janium/MEP/memorias.html.

Ministerio de Educación Pública. (1978). Memoria anual de labores 1977. Recuperado de: http://mep.janium.net/janium/MEP/memorias.html.

Ministerio de Educación Pública. (1982). Memoria anual de labores 1981. Recuperado de: http://mep.janium.net/janium/MEP/memorias.html.

Ministerio de Educación Pública. (1990). Memoria anual de labores. Recuperado de http://mep.janium.net/janium/MEP/memorias.html.

Ministerio de Educación Pública. (1997). Memoria anual de labores 1996-1997. Recuperado de: http://mep.janium.net/janium/MEP/memorias.html

Ministerio de Educación Pública. (1994). Memoria anual de labores 1993-1994. Recuperado de: http://mep.janium.net/janium/MEP/memorias.html.

Ministerio de Educación Pública. (2008). Memoria institucional 2006-2008. Recuperado de http://mep.janium.net/janium/MEP/memorias.html.

Ministerio de Educación Pública. (2014). "La Educación Subversiva: Atreverse a construir el país que queremos" Memoria Institucional MEP 2006 - 2014. Recuperado de: http://www.mep.go.cr/memoria-institucional-2006-2014.

Ministerio de Educación Pública. (2015a). Evolución de los indicadores de la Educación Técnica Profesional en Costa Rica en el periodo 2000-2014. Recuperado de: http://www.mep.go.cr/indicadores edu/indice boletines.html 
Ministerio de Educación Pública. (2015b). Colegios diurnos y nocturnos. Dependencia pública, privada y privada-subvencionada según dirección regional y circuito escolar año 2015. Departamento de Estadística. Archivo institucional.

Molina, Lorena. y Morera, Nidia. (1994). La investigación en políticas sociales: un enfoque del Trabajo Social. Recuperado de http://www.ts.ucr.ac.cr/binarios/docente/pd000121.pdf

O'Donnell, Guillermo. y Oszlak, Oscar. (1981). Estado y políticas estatales en América Latina: hacia una estrategia de investigación. Buenos Aires, Argentina: Centro de Estudios de Estado y Sociedad (CEDES). Recuperado de http://politicayplanificacionsocial.sociales.uba.ar/files/2012/04/04.05.-Dossier-Estado-ypoliticas-estatales-en-America-Latina1.pdf

Paredes, Ilda. (2008). Influencia del enfoque sistémico en el Trabajo Social. Perú: Universidad Nacional del Altiplano. Recuperado de http://www.ts.ucr.ac.cr/binarios/pela/pl-000309.pdf

Parsons, Wayne. (2007). Políticas Públicas: una introducción a la teoría y la práctica del análisis de políticas públicas. México: FLACSO.

Programa Estado de la Nación. (2011). III Informe del Estado de la Educación. San José, Costa Rica. Recuperado de http://www.estadonacion.or.cr/estadoeducacion/educacion-por-capitulo/educacion-informe2011

Rojas, Carlos. (1977). Cronología comentada de la educación técnica en Costa Rica. San José, Costa Rica: Ministerio de Educación Pública, Dirección General de Educación Técnica Profesional.

Quesada, Juan. (2005). Un siglo de educación costarricense 1814-1914. Cuadernos de Historia de las Instituciones de Costa Rica, 23. San José, Costa Rica: Editorial de la Universidad de Costa Rica.

Velásquez, Raúl. (2009). Hacia una nueva definición de del concepto "política pública". Desafíos, (20), 149-187. Recuperado de http://revistas.urosario.edu.co/index.php/desafios/article/viewArticle/433 
Revista indizada en

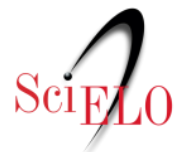

redalyc satindex

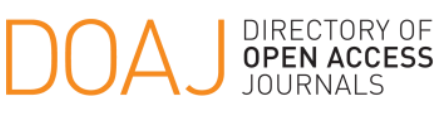

Distribuida en las bases de datos:

๑ Dialnet

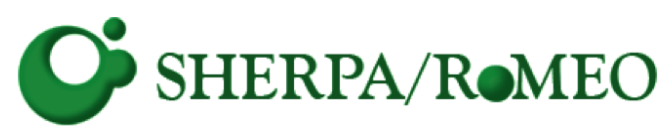

REDIB

Red Iberoamericana

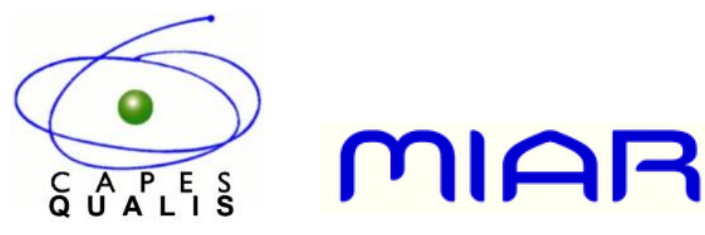

